\title{
Systematic Elucidation of Factors that Influence the Strength of Tetrel Bonds
}

\author{
Steve Scheiner* \\ Department of Chemistry and Biochemistry \\ Utah State University \\ Logan, UT 84322-0300
}

*email: steve.scheiner@usu.edu

phone: 435-797-7419

\begin{abstract}
Quantum calculations are used to examine the properties of heterodimers formed by a series of tetrel-containing molecules with $\mathrm{NH}_{3}$ as universal Lewis base. $\mathrm{TH}_{4}$ was taken as a starting point, with $\mathrm{T}=\mathrm{C}, \mathrm{Si}, \mathrm{Ge}$, and $\mathrm{Sn}$. The $\mathrm{H}$ atoms were replaced by various numbers of $\mathrm{F}$ atoms: $\mathrm{TH}_{3} \mathrm{~F}, \mathrm{TF}_{3} \mathrm{H}$, and $\mathrm{TF}_{4}$ so as to monitor the effects of adding electron-withdrawing substituents. Unsubstituted $\mathrm{TH}_{4}$ molecules form the weakest tetrel bonds, only up to about $2 \mathrm{kcal} / \mathrm{mol}$. The bond is strengthened when the $\mathrm{H}$ opposite $\mathrm{NH}_{3}$ is replaced by $\mathrm{F}$, rising up to the 6-9 $\mathrm{kcal} / \mathrm{mol}$ range. Another means of strengthening arises when the three peripheral $\mathrm{H}$ atoms of $\mathrm{TH}_{4}$ are replaced by $F$. The effect of the latter is heavily dependent on the nature of the $T$ atom, and is particularly noticeable for larger tetrels. The two sorts of fluorination patterns are cooperative, in that their combination in $\mathrm{TF}_{4}$ yields by far the most powerful tetrel bonding agent. The tetrel bond is strengthened as the $\mathrm{T}$ atom moves further down the periodic table column. The strongest bond amounts to $25.5 \mathrm{kcal} / \mathrm{mol}$ for $\mathrm{SnF}_{4} \bullet \mathrm{NH}_{3}$. A number of features correlate with the binding energy, but only roughly. These properties include the charge transfer, the AIM bond critical point electron density, the molecular electrostatic potential, and the stretch of the T-X covalent bond upon complex formation.
\end{abstract}




\section{INTRODUCTION}

Although much weaker than their covalent counterparts, noncovalent forces play essential roles in a broad range of chemical and biological phenomena that range from solvation to crystallization, from biomolecular structure to the transmission of the genetic code. Of the various noncovalent interactions, probably the most thoroughly studied over the years is the H-bond (HB) ${ }^{1-3}$. The uniqueness of the HB has been challenged by the finding that the bridging proton can be replaced by any of a large collection of much more electronegative atoms, with little loss in interaction energy. For example, a halogen $(\mathrm{X})$ atom can serve a similar bridging function $^{4-10}$. The strong anisotropy of the charge distribution around the halogen atom permits it to serve in more than one capacity, as both electron donor and acceptor. The partial positive charge that develops opposite the R-X bond facilitates its interaction with an approaching nucleophile, in much the same way as the polarity of a O-H bond guides an electron donor into position along the $\mathrm{O}-\mathrm{H}$ axis in the formation of a $\mathrm{HB}$. Halogen bonds are not unique in this regard. There is growing recognition that atoms from the chalcogen and pnicogen families have a similar functionality ${ }^{11-21}$.

The tetrel family of atoms, headed by $\mathrm{C}$ and $\mathrm{Si}$, also appear able to serve in this capacity ${ }^{22-40}$. These sorts of bonds appear to be important in a number of processes including chemical reactions, molecular recognition, and the structure of materials ${ }^{41-45}$. This capability to form a noncovalent bond is perhaps a bit surprising due to steric constraints. That is, since tetrel atoms are usually tetravalent, and since the nucleophile tends to approach along the extension of one of these covalent bonds, it might be difficult for the nucleophile to squeeze itself in between the other three substituents bonded to the tetrel atom. Taking a purely tetrahedral $\mathrm{TR}_{4}$ molecule as an example (where T refers to a tetrel atom), a position opposite one of the T-R bonds would place the nucleophile within $70^{\circ}$ of the other three T-R bonds. It is for this reason that the formation of a tetrel bond repels the three covalent T-R bonds, and the final structure tends to resemble a trigonal bipyramid to a certain extent. On the positive side, the lesser electronegativity of tetrel atoms, as compared to pnicogens, chalcogens, and especially halogens, ought to enable a more positive electrostatic potential to better attract an approaching nucleophile.

Three are several general features of tetrel bonds that have emerged from earlier work. Much like their pnicogen, halogen, and chalcogen cousins, there is a tendency for tetrel bonds to strengthen as the $\mathrm{T}$ atom moves further down this column of the periodic table. The placement of electron withdrawing substituents on the $\mathrm{T}$ atom, especially directly opposite the approaching nucleophile, also acts to strengthen the tetrel bond. What is missing in the literature at this point is a fundamental and systematic examination of how various aspects of the tetrel-bonding molecule combine with one another. Specifically, does the tetrel bond always strengthen as one moves down the tetrel column of the periodic table, regardless of substituent? What is the quantitative effect of progressively adding electron-withdrawing substituents on the tetrel, one by one? How 
does the presence of a single electron-withdrawing substituent, positioned opposite the Lewis base, compare with several such substituents in peripheral positions? Do these two types of substituent positions act cooperatively when both are present, or do they counteract one another to some extent? And are these trends typical of all tetrel atoms, or do they change when the atom becomes heavier and less electronegative? This work attempts to answer these questions via quantum chemical calculations in a highly systematic manner. A wide range of molecules that have the potential to engage in tetrel bonds are considered, that include four different tetrel atoms, each bonded to a varying number of highly electron-withdrawing substituents.

\section{SYSTEMS AND METHODS}

The tetrel atoms (abbreviated as T) considered here are C, $\mathrm{Si}, \mathrm{Ge}$, and $\mathrm{Sn}$. The unsubstituted $\mathrm{TH}_{4}$ molecules were each taken as a starting point Lewis acid. $\mathrm{NH}_{3}$ was used as the universal electron donor, due to its simplicity, containing a single lone pair and with no $\pi$ bonds that might complicate the analysis. $\mathrm{The}^{\mathrm{NH}} \mathrm{Was}_{3}$ positioned directly opposite one of the $\mathrm{H}$ atoms of $\mathrm{TH}_{4}$ and the entire geometry of the complex fully optimized. The $\mathrm{H}$ atoms of $\mathrm{TH}_{4}$ were progressively replaced by $\mathrm{F}$ substituents, due to its high electron-withdrawing power. Upon single replacement, the $\mathrm{F}$ atom of $\mathrm{TH}_{3} \mathrm{~F}$ was positioned directly opposite the $\mathrm{N}$ atom of $\mathrm{NH}_{3}$ in order to quantify how the more electronegative $\mathrm{F}$ might strengthen the tetrel bond in this position. In an alternate scenario, the $\mathrm{NH}_{3}$ was located directly opposite the $\mathrm{T}-\mathrm{H}$ bond, but the other three $\mathrm{H}$ atoms of $\mathrm{TH}_{4}$ were all replaced by $\mathrm{F}$, forming $\mathrm{TF}_{3} \mathrm{H}$ as Lewis acid. This formulation facilitates an understanding of how the electronwithdrawing capability of these three $\mathrm{F}$ atoms might act to strengthen the HT $\bullet \mathrm{N}$ tetrel bond. The final step is the replacement of the sole remaining $\mathrm{H}$ atom by $\mathrm{F}$, providing a FT $\bullet \cdot \mathrm{N}$ tetrel bond with $\mathrm{TF}_{4}$ which can be compared with the previous three arrangements.

The Gaussian-09 ${ }^{46}$ program was employed for all calculations which were carried out at the MP2 level using the aug-cc-pVDZ basis set. The aug-cc-pVDZ-PP pseudopotential from the EMSL library ${ }^{47-48}$ was used for Sn so as to account for relativistic effects. This level of theory has demonstrated its accuracy and effectiveness in numerous previous studies ${ }^{49-61}$ of related systems.

All geometries were fully optimized, and checked to ensure they were true minima, containing all positive vibrational frequencies. The complexation/association energy, $\Delta \mathrm{E}^{\text {elec }}$, was defined as the difference between the energy of the complex and the sum of the energies of separately optimized monomers. Basis set superposition error was removed via the counterpoise ${ }^{62}$ procedure. Free energies at $298 \mathrm{~K}$ were computed using standard physical chemistry formulae. Molecular electrostatic potential maps were visualized via the Chemcraft program ${ }^{63}$ and further quantified by WFA-SAS ${ }^{64}$. The Natural Bond Orbital (NBO) technique ${ }^{65}$ was used to provide quantitative measures of charge transfer. The topology of the electron density was assessed within the AIM ${ }^{66-67}$ context, with values computed by AIMALL ${ }^{68}$. 


\section{RESULTS}

\section{Geometry and Energetics}

The $\mathrm{N}$ atom of $\mathrm{NH}_{3}$ was optimized to lie in a position directly opposite one $\mathrm{H} / \mathrm{F}$ atom of the Lewis acid. Typical structures are displayed in Table 1 for the Ge tetrel atoms wherein the $\theta(\mathrm{H} / \mathrm{F}-\mathrm{Ge} \cdot \cdot \mathrm{N})$ angle is $180^{\circ}$, and all of these dimers belong to the $\mathrm{C}_{3 \mathrm{v}}$ point group, as was also the case for the corresponding complexes involving Sn and Si. One can see the shortening of the $\mathrm{R}\left(\mathrm{Ge} \cdot{ }^{\circ} \mathrm{N}\right)$ intermolecular distances as more $\mathrm{F}$ atoms are added to the Lewis acid, from a maximum of $3.33 \AA$ for $\mathrm{GeH}_{4}$ down to a minimum of $2.11 \AA$ for $\mathrm{GeF}_{4}$. The separations of the other complexes are reported on the left side of Table 1, where a similar trend is evident for the other tetrel atoms as well. Note that the weakness of $\mathrm{C}$ as an electron acceptor leads to the absence of a tetrel-bonded complex for either $\mathrm{CH}_{4}$ or $\mathrm{CF}_{3} \mathrm{H}$. Even when a tetrel bond is formed, for $\mathrm{CH}_{3} \mathrm{~F}$ and $\mathrm{CF}_{4}$, the intermolecular separation is quite long, more than $3 \AA$, and the relevant $\theta(\mathrm{FC} \cdot \cdot \mathrm{N})$ angle deviates from $180^{\circ}$. Scanning further down each column of Table 1 shows a fairly small sensitivity of $R$ to the nature of the tetrel atom, for those beyond $\mathrm{C}$. This pattern can be attributed to two competing effects. On one hand, the larger $\mathrm{T}$ atoms would tend toward a greater separation. But, as detailed below, the larger tetrel atoms also yield stronger tetrel bonds, which tend to pull the molecules closer together.

The energetics of the formation of each tetrel bond are contained in Table 2. $\Delta \mathrm{E}^{\text {elec }}$ refers to the electronic contribution to this complexation, while the free energies contain the vibrational and entropic effects as well. As anticipated, the binding energies are quite weak for the C-tetrel bonds, less than $2 \mathrm{kcal} / \mathrm{mol}$, when such a bond exists at all. Even the nonfluorinated $\mathrm{TH}_{4}$ molecules engage in a tetrel bond, albeit not very strong. Placing a single $\mathrm{F}$ atom on the Lewis acid, directly opposite the $\mathrm{NH}_{3}$, very substantially strengthens the interaction, by a factor between 3 and 4 . Leaving $\mathrm{H}$ as the atom opposite the base, but surrounding it by three $\mathrm{F}$ atoms has a variable effect. Whereas $\mathrm{TF}_{3} \mathrm{H}$ binds slightly less strongly than does $\mathrm{TH}_{3} \mathrm{~F}$ for $\mathrm{Si}$, the opposite occurs for $\mathrm{Ge}$, and especially for $\mathrm{Sn}$ where this change more than doubles $\Delta \mathrm{E}$. The combination, wherein the opposite atom is $\mathrm{F}$, as are the three surrounding atoms, leads to a further, and rather large, increment in $\Delta \mathrm{E}$. The strongest tetrel bond, amounting to $25.5 \mathrm{kcal} / \mathrm{mol}$, occurs for $\mathrm{SnF}_{4} \cdot \mathrm{NH}_{3}$. To place this quantity in perspective, it is roughly five times larger than the paradigmatic H-bond in the water dimer.

The reduction in entropy associated with the dimerization tends to weaken each of these interactions. Many of the values of $\Delta \mathrm{G}$ on the right side of Table 2 are hence positive. Nonetheless, the latter quantities reflect the trends in $\Delta \mathrm{E}$ on the left side of the table, even if not quantitatively identical. The strongest interaction remains that in $\mathrm{SnF}_{4} \cdot \cdot \mathrm{NH}_{3}$, with $\Delta \mathrm{G}=-13.4 \mathrm{kcal} / \mathrm{mol}$. 


\section{Contributing Factors}

There are a number of means of understanding the relative strengths of the interactions. The AIM procedure allows one to assess the strength via the electron density occurring at the bond critical point that connects the tetrel and base $\mathrm{N}$ atoms. These quantities are presented in Table 3, and can be compared with the energetics in Table 2. In either case, the $\mathrm{C}$ atom engages in the weakest tetrel bonds, and the progressive fluorination of the Lewis acid enhances these bonds. There are also certain discrepancies between the two measures of the bond. For example, the largest value of $\varrho_{\mathrm{BCP}}$ occurs for $\mathrm{GeF}_{4} \cdot \mathrm{NH}_{3}$ rather than $\mathrm{SnF}_{4} \cdot \mathrm{NH}_{3}$. Nor does $\varrho_{\mathrm{BCP}}$ accurately reflect the large energetic increment on going from trifluorinated to tetrafluorinated Lewis acid. It should perhaps be stressed that comparisons of BCP densities between different pairs of atoms, e.g. Ge/N and Sn/N, can introduce certain inconsistencies that might affect these correlations, although such applications are quite common in the literature ${ }^{39-40,44,69}$ and have shown some genuine use.

A certain degree of contribution to the tetrel bond resides in the charge transfer from the base to the acid. One can measure this quantity first as an interorbital transfer from the $\mathrm{N}$ lone pair to the $\sigma^{*}(\mathrm{~T}-\mathrm{X})$ antibonding orbital where $X$ represents the atom directly opposite the $N$. The corresponding values of $E(2)_{1}$ in the NBO formalism are listed on the left side of Table 4. It is not only the atom which lies directly opposite the Lewis base to which charge is added, but the other atoms as well. These charge transfers are listed in the second section of Table 4, as $\mathrm{E}(2)_{2}$. When these peripheral atoms are $\mathrm{H}$, much less charge is deposited into their $\sigma^{*}$ antibonding orbitals as compared to the opposite atom. But this transfer is much greater for $\mathrm{F}$ atoms, and can even exceed the amount for the opposite atom, particularly when the latter is a hydrogen. The total transfer of

charge from the Lewis base molecule to the acid is also displayed in Table 4, as the sum of charges of all atoms on the $\mathrm{NH}_{3}$ molecule. As was the case for the AIM measure, these charge transfer parameters provide a reasonable, but far from perfect reflection of bond strength. While $\mathrm{C}$ is clearly a marginal tetrel-bonding atom, there is little distinction between $\mathrm{Si}, \mathrm{Ge}$, and $\mathrm{Sn}$. In fact, $\mathrm{E}(2)_{1}$ predicts a $\mathrm{Si}>\mathrm{Ge}>\mathrm{Sn}$ energetic ordering of $\mathrm{TF}_{3} \mathrm{H} \cdot \mathrm{NH}_{3}$, whereas the opposite is true. Nor does $\mathrm{E}(2)_{1}$ correctly reflect the comparison of $\mathrm{TH}_{3} \mathrm{~F}$ with $\mathrm{TF}_{3} \mathrm{H}$. The total charge transfer does not show any real difference between $\mathrm{TF}_{3} \mathrm{H}$ and $\mathrm{TF}_{4}$, although the latter forms much stronger bonds. Some of these discrepancies between binding energy and measures of charge transfer may be taken to indicate that this phenomenon is not the major contributor to the interaction.

As a corollary of the transfer of charge into the $\sigma^{*}(\mathrm{~T}-\mathrm{X})$ antibonding orbital, one can anticipate a weakening and concomitant lengthening of this covalent bond. This bond stretch is reported on the right side of Table 1. Like the energetic aspect of this transfer, $\mathrm{E}(2), \Delta \mathrm{r}(\mathrm{T}-\mathrm{X})$ also is not an accurate barometer of bond strength. Neither captures the strong dependence of binding strength on the nature of the tetrel atom in the $\mathrm{TF}_{4} \cdot \mathrm{NH}_{3}$ dimers. Regardless of the bond strength $\Delta r(T-F)$ is consistently larger than $\Delta r(T-H)$. It should be noted as well 
that it is not only the $\mathrm{X}$ atom that lies directly opposite $\mathrm{N}$ that elongates; the three peripheral atoms also move further from $\mathrm{T}$ upon formation of the complex.

Past work has shown that Coulombic forces make a major contribution ${ }^{38-39,70}$ to noncovalent forces such as tetrel and hydrogen bonds. Perhaps the simplest way of considering this issue would be an examination of the dipole-dipole component of the multipolar expansion. Whereas the symmetry of both $\mathrm{TH}_{4}$ and $\mathrm{TF}_{4}$ exclude a dipole moment, both partially fluorinated molecules have such a moment. However, they are pointing in opposite directions. That is, the moment of $\mathrm{TH}_{3} \mathrm{~F}$ is aligned so that its positive end points toward the negative dipole of the incoming $\mathrm{NH}_{3}$, a favorable situation. The alignment is, in contrast, destabilizing for $\mathrm{TF}_{3} \mathrm{H}$ where the negative ends of the two molecular dipoles point toward one another. From this simple perspective, then, the $\mathrm{TH}_{3} \mathrm{~F} \bullet \bullet \mathrm{NH}_{3}$ complexation energies are boosted by dipole-dipole forces, while this same factor tends to weaken the tetrel bond in $\mathrm{TF}_{3} \mathrm{H} \bullet \bullet \mathrm{NH}_{3}$. This discrepancy rises along with the size of the tetrel atom. The dipole moment of the $\mathrm{TH}_{3} \mathrm{~F}$ molecule increases from $1.68 \mathrm{D}$ for $\mathrm{T}=\mathrm{Si}$ up to 2.94 for $\mathrm{Sn}$, and that of $\mathrm{TF}_{3} \mathrm{H}$ undergoes a similar rise from 1.72 to $3.38 \mathrm{D}$.

A far more complete view of Coulombic forces, surpassing the simplistic dipole-dipole picture, is offered by consideration of the full molecular electrostatic potential (MEP) surrounding each subunit. The MEP of each Lewis acid is illustrated in Fig 2, where the most positive regions are shown in blue and red indicates the most negative areas. The location of most interest lies to the right of each tetrel atom, directly opposite the $\mathrm{H}$ or $\mathrm{F}$ atom, where the $\mathrm{N}$ atom of $\mathrm{NH}_{3}$ nestles itself within the complex, the so-called $\sigma$-hole.

Considering first the C-containing molecules in the top row, there does not appear to be a $\sigma$-hole for $\mathrm{CH}_{4}$, as the most positive regions lie on the $\mathrm{H}$ end of each $\mathrm{C}-\mathrm{H}$ bond. The most intensely blue areas occur in the $\sigma$-hole location for $\mathrm{CH}_{3} \mathrm{~F}$ and $\mathrm{CF}_{4}$, both of which engage in a tetrel bond. It is also $\mathrm{TH}_{3} \mathrm{~F}$ and $\mathrm{TF}_{4}$, which contain the most intense $\sigma$-holes for the other Lewis acids. However, the other tetrels differ from $\mathrm{C}$ in that there is also a visible $\sigma$-hole for $\mathrm{TH}_{4}$ and $\mathrm{TF}_{3} \mathrm{H}$, albeit less intense ones. The pictorial MEPs are consistent with the observed weakness of the tetrel bonds for $\mathrm{TH}_{4}$. On the other hand, they do not adequately explain the stronger tetrel bonds for $\mathrm{TF}_{4}$ than for the others, and would incorrectly predict that $\mathrm{TH}_{3} \mathrm{~F}$ ought to engage in stronger bonds than $\mathrm{TF}_{3} \mathrm{H}$. There is also little to distinguish one tetrel atom from another, e.g. no visual evidence that $\mathrm{SnF}_{4}$ should engage in a stronger tetrel bond than any other $\mathrm{TF}_{4}$.

This sort of MEP analysis can be placed on a more quantitative footing by locating the extrema on a surface that surrounds each molecule. It is common to choose for the latter an isodensity surface, most often that for $\mathrm{Q}=0.001 \mathrm{au}$. The value of the maximum on this surface, defined as $\mathrm{V}_{\mathrm{s}, \max }$, in the vicinity of the $\sigma$-hole, is reported in Table 5 for each Lewis acid. As suggested by the pictorial version in Fig 2, there is no such minimum for $\mathrm{CH}_{4}$, but all other molecules do have a MEP minimum in the appropriate location. For any given 
column in Table 5, $\mathrm{V}_{\mathrm{s}, \text { max }}$ increases in the $\mathrm{C}<\mathrm{Si}<\mathrm{Ge}<\mathrm{Sn}$ sequence, although this pattern is disrupted a bit for $\mathrm{TH}_{4}$ and $\mathrm{TF}_{3} \mathrm{H}$ when $\mathrm{T}=\mathrm{Si}$ and $\mathrm{Ge}$. This trend is fairly consistent with the energetics in Table 2. Also in common with $\Delta \mathrm{E}$, the weakest and strongest complexes are formed respectively by $\mathrm{TH}_{4}$ and $\mathrm{TF}_{4}$. On the other hand, whereas $\mathrm{TF}_{3} \mathrm{H}$ usually engages in a stronger tetrel bond than does $\mathrm{TH}_{3} \mathrm{~F}$, it is the latter which has the larger value of $\mathrm{V}_{\mathrm{s} \text {,max }}$. In other words, a position opposite $\mathrm{F}$ is associated with a stronger $\sigma$-hole than $\mathrm{H}$, even when the latter has the benefit of three highly electron-withdrawing $\mathrm{F}$ atoms bonded to the tetrel atom. But it is the latter arrangement, opposite the $\mathrm{H}$, which corresponds to the stronger tetrel bond.

In summary, whether the pictorial version of the MEP, or its magnitude at a single point, this potential offers some important clues as to the strength of the tetrel bond it is capable of forming. However, like the electron density topological data, measures of charge transfer, or internal bond stretching, the MEP too provides only an imperfect means of predicting the strength of the tetrel bond.

Because the Lewis base must insert itself between the three peripheral T-Y bonds of the Lewis acid, which are roughly only $109^{\circ}$ apart, the formation of the complex must pry these latter three bonds apart to a certain extent. The change in the internal $\theta(\mathrm{X}-\mathrm{T}-\mathrm{Y})$ angle, where $\mathrm{X}$ lies opposite $\mathrm{N}$ and $\mathrm{Y}$ represents one of the three peripheral atoms bonded to $\mathrm{T}$, is recorded on the left side of Table 6 . These distortions fit a fairly regular pattern in that the angle changes very little, $1-3^{\circ}$ for $\mathrm{TH}_{4}$, some $5^{\circ}$ for $\mathrm{TH}_{3} \mathrm{~F}$, and $11-13^{\circ}$ for $\mathrm{TF}_{3} \mathrm{H}_{\text {and }} \mathrm{TF}_{4}$, which are very similar to one another. Note that the negative values of these angular changes signal the motion of the peripheral atoms away from the Lewis base. The larger deformations for the $\mathrm{TF}_{3} \mathrm{H}$ and $\mathrm{TF}_{4}$ substitution patterns make sense in that the larger $\mathrm{F}$ atoms must spread further apart to make room for the approaching $\mathrm{NH}_{3}$, than do the smaller $\mathrm{H}$ atoms. There is very little sensitivity to the identity of the $\mathrm{T}$ atom, except of course the miniscule changes for $\mathrm{T}=\mathrm{C}$.

These realignments, coupled with bond length changes, have an energetic consequence. The right side of Table 6 denotes the rise in the energy of the Lewis acid molecule caused by its deformation from its fully optimized geometry to the structure it adopts within the dimer. As expected, $\mathrm{E}_{\mathrm{def}}$ is quite small for $\mathrm{TH}_{4}$, and rises to nearly $2 \mathrm{kcal} / \mathrm{mol}$ for $\mathrm{TH}_{3} \mathrm{~F}$. This quantity increases a good deal upon further fluorosubstitution, to the $10-20 \mathrm{kcal} / \mathrm{mol}$ range, as the angular deformations are larger here. It is a bit larger for $\mathrm{TF}_{3} \mathrm{H}$ than for $\mathrm{TF}_{4}$. Opposite to the pattern of binding energies, $\mathrm{E}_{\mathrm{def}}$ diminishes as the $\mathrm{T}$ atom grows larger, in the order $\mathrm{Si}>\mathrm{Ge}>$ $\mathrm{Sn}$. These deformation energies, some of them rather large, must be overcome in order for the complex to form. Taking the $\mathrm{SnF}_{4} \cdot \mathrm{NH}_{3}$ dimer as an example, its $25.53 \mathrm{kcal} / \mathrm{mol}$ binding energy (Table 2) must overcome a 9.62 $\mathrm{kcal} / \mathrm{mol}$ deformation energy. The interaction energy between the two subunits, after deforming to their geometries within the dimer, is thus on the order of $35 \mathrm{kcal} / \mathrm{mol}$. Likewise, this interaction energy exceeds 30 $\mathrm{kcal} / \mathrm{mol}$ for the other perfluoro-tetrel bonded species $\mathrm{SiF}_{4} \cdot \mathrm{NH}_{3}$ and $\mathrm{GeF}_{4} \cdot \mathrm{NH}_{3}$. In a more general sense, 
although these quantities obey the same $\mathrm{Si}<\mathrm{Ge}<\mathrm{Sn}$ trend as does $\Delta \mathrm{E}$ in Table 1 , the interaction energy is less sensitive to the identity of the tetrel atom. It also shows a much larger increase on going from $\mathrm{TH}_{3} \mathrm{~F}$ to $\mathrm{TF}_{3} \mathrm{H}$.

\section{SUMMARY AND DISCUSSION}

Tetrel bonds occur with widely varying strength. The unsubstituted $\mathrm{TH}_{4}$ molecules form the weakest, only up to about $2 \mathrm{kcal} / \mathrm{mol} ; \mathrm{CH}_{4}$ does not engage in such bonds at all. The interaction is strengthened when the $\mathrm{H}$ opposite the Lewis base is replaced by F, rising up to the $6-9 \mathrm{kcal} / \mathrm{mol}$ range. Another means of strengthening the tetrel bond is the substitution of the three peripheral $\mathrm{H}$ atoms of $\mathrm{TH}_{4}$ by $\mathrm{F}$, even when an $\mathrm{H}$ atom remains directly opposite the base. The effect of this substitution pattern is heavily dependent on the nature of the $\mathrm{T}$ atom, and is particularly noticeable for heavier tetrels. The combination, wherein the opposite atom is replaced by $\mathrm{F}$, as are the three peripheral atoms, makes $\mathrm{TF}_{4}$ by far the most powerful tetrel bonding agent. With only a minor exception, the interaction increases as $\mathrm{C}<\mathrm{Si}<\mathrm{Ge}<\mathrm{Sn}$. With all of these factors taken into account, the strongest tetrel bond association energy amounts to $25.5 \mathrm{kcal} / \mathrm{mol}$ for $\mathrm{SnF}_{4} \bullet \mathrm{NH}_{3}$. The destabilizing effects of vibrational energy and entropy vis a vis the association reaction leads generally to positive values of $\Delta \mathrm{G}$ at 298 $\mathrm{K}$. The exceptions, with a negative $\Delta \mathrm{G}$, occur for the strongest of the tetrel bonds. In any case, the various trends observed for $\Delta \mathrm{E}$ are reproduced fairly closely by $\Delta \mathrm{G}$.

There are several properties that tend to correlate with the energetics. The electron density of the bond critical point located between the $\mathrm{T}$ and $\mathrm{N}$ atoms tends to mirror the association energy to some extent but this correlation suffers from certain discrepancies. The same can be said of the measures of charge transfer, either between pertinent MOs or between the molecules as a whole. Inspection of the molecular electrostatic potential offers a window into the Coulombic segment of the interaction. The extent and intensity of the positive segment of the MEP on the Lewis acid correlates fairly well with the total binding energy, but again there are certain discrepancies in the trends of the two. The failure of any one particular component to correlate much more closely with the binding energy is an indication that all aspects of the interaction are important and cannot be ignored.

In terms of geometries, the $\mathrm{R}(\mathrm{T} \bullet \bullet \mathrm{N})$ intermolecular separation for any given $\mathrm{T}$ atom contracts as $\mathrm{H}$ atoms are replaced by $\mathrm{F}$ and the tetrel bond strengthens. On the other hand, there is a natural tendency for this distance to elongate as the $\mathrm{T}$ atom moves down the periodic table and its atomic radius increases. These two trends tend to oppose one another. Consequently, the shortest tetrel bond of $2.054 \AA$ occurs for $\mathrm{SiF}_{4} \bullet \mathrm{NH}_{3}$. But it is quite notable that this length is only $2.279 \AA$ A even for the large $\mathrm{Sn}$ atom in $\mathrm{SnF}_{4} \bullet \mathrm{NH}_{3}$. The shift of density into the $\sigma^{*}(\mathrm{~T}-\mathrm{X})$ antibonding orbital causes a lengthening of this covalent bond. This bond stretch does not correlate very well with association energy; it is particularly large for $\mathrm{X}=\mathrm{F}$, rising up to a maximum of $0.034 \AA$ for $\mathrm{SnH}_{3} \mathrm{~F} \bullet \bullet \mathrm{NH}_{3}$. 
In summary, then, there is a tendency for the tetrel bond strength to increase as the tetrel atom descends along the periodic table column. It is certainly true that $\mathrm{Sn}$ forms the strongest bonds and $\mathrm{C}$ the weakest. However, $\mathrm{Si}$ and Ge are fairly similar in this respect for $\mathrm{TH}_{4}$ and $\mathrm{TH}_{3} \mathrm{~F}$, although Ge forms clearly stronger bonds for the more heavily fluorinated $\mathrm{TF}_{3} \mathrm{H}$ and $\mathrm{TF}_{4}$. For the two heavier Ge and $\mathrm{Sn}$ atoms, a stronger tetrel bond is formed when the $\mathrm{H}$ atom lies opposite the base, and it is surrounded by electron-withdrawing atoms, than the reverse situation wherein the F-T••N tetrel bond does not have the benefit of three surrounding $\mathrm{F}$ atoms.

A question posed earlier related to the possibly synergistic effects of i) the placement of an electronwithdrawing substituent opposite the Lewis base, and ii) addition of such substituents on the $\mathrm{T}$ atom, but not directly opposite the base. One can examine this issue via the data in Table 2. Taking the Si series as an example, the replacement of the $\mathrm{H}$ atom of $\mathrm{SiH}_{4}$ directly opposite the $\mathrm{NH}_{3}$ by $\mathrm{F}$ raises the binding energy from 1.66 to $5.49 \mathrm{kcal} / \mathrm{mol}$, an increase of 3.83. If instead, the other three $\mathrm{H}$ atoms of $\mathrm{SiH}_{4}$ are replaced by $\mathrm{F}$, this increment is $3.09 \mathrm{kcal} / \mathrm{mol}$. If these two effects were purely additive, one might expect the binding energy of $\mathrm{SiF}_{4}$ to be $(3.83+3.09)$, or $6.92 \mathrm{kcal} / \mathrm{mol}$. However, Table 2 shows the difference in binding energy between $\mathrm{SiH}_{4}$ and $\mathrm{SiF}_{4}$ to be $8.93,2.0 \mathrm{kcal} / \mathrm{mol}$ larger than the sum of the two effects separately. In other words, these two types of substitutions act to augment one another in a cooperative fashion. This augmentation is even larger for Ge, amounting to $3.7 \mathrm{kcal} / \mathrm{mol}$, but smaller, $1.3 \mathrm{kcal} / \mathrm{mol}$, for $\mathrm{Sn}$. But in all three sets of systems, one does see the two sorts of substitutions acting in concert, with the whole greater than the sum of its parts. This analysis cannot be applied to $\mathrm{C}$, since neither $\mathrm{CH}_{4}$ nor $\mathrm{CF}_{3} \mathrm{H}$ engage in tetrel bonding with $\mathrm{NH}_{3}$. But it is intriguing that the tetrel bond formed by $\mathrm{CF}_{4}$ is appreciably weaker than that involving $\mathrm{CH}_{3} \mathrm{~F}$. This phenomenon may be due to the presence of a stabilizing dipole-dipole interaction in $\mathrm{CH}_{3} \mathrm{~F} \cdot \mathrm{NH}_{3}$, which is absent for $\mathrm{CF}_{4} \cdot \cdot \mathrm{NH}_{3}$, as $\mathrm{CF}_{4}$ has no permanent dipole.

These results can be placed in the context of prior calculations. Although restricted to Si, an early work ${ }^{36}$ had suggested that tetrafluorosilane was bound to $\mathrm{NH}_{3}$ much more strongly than unsubstituted silane. Later calculations ${ }^{23,37}$ also confined to $\mathrm{Si}$, had confirmed the stabilizing effects of fluorosubstitution, and were consistent with our own finding here that $\mathrm{SiH}_{3} \mathrm{~F}$ binds more strongly than does $\mathrm{SiF}_{3} \mathrm{H}$ when it is the $\mathrm{F}$ atom that is directly opposite the Lewis base in the former case, as further confirmed by a more recent study of Si-based tetrel bonds ${ }^{71}$. Experimental measurements ${ }^{35}$ have provided evidence that $\mathrm{Si} \cdot \mathrm{N}$ tetrel bonds can occur in an intramolecular setting as well.

Grabowski ${ }^{24}$ had recently expanded the range of tetrel atoms up through Ge, but used different Lewis bases than $\mathrm{NH}_{3}$, including a $\mathrm{Cl}^{-}$anion. Nonetheless, there was a clear trend of stronger interactions in the sequence $\mathrm{C}$ $<\mathrm{Si}<\mathrm{Ge}$. With NCH as Lewis acid, binding energies were considerably smaller than those computed here 
with $\mathrm{NH}_{3}$. For example, the binding energy of $\mathrm{GeF}_{4} \cdot{ }^{\bullet} \mathrm{NCH}$ is only $4.1 \mathrm{kcal} / \mathrm{mol}$, in comparison with 16.8 $\mathrm{kcal} / \mathrm{mol}$ computed here for $\mathrm{GeF}_{4} \bullet \mathrm{NH}_{3}$. Another peculiarity of $\mathrm{NCH}$ is that its binding energy is somewhat smaller for $\mathrm{TF}_{4}$ than for $\mathrm{TF}_{3} \mathrm{H}$, for any of the tetrel atoms $\mathrm{C}, \mathrm{Si}$, or $\mathrm{Ge}$, quite the opposite to the behavior of $\mathrm{NH}_{3}$, where $\mathrm{TF}_{4}$ binds much more strongly. This $\mathrm{NCH}$ anomaly was corrected when it was replaced by NCLi. A recent study of larger systems known as atranes ${ }^{72}$ noted that tetrel bonds involving $\mathrm{C}, \mathrm{Si}$, and $\mathrm{Ge}$ could be formed in an intramolecular context but did not directly evaluate their energies nor consider substituent effects

Heavier tetrel atoms have not been entirely ignored. The Sn॰ $\bullet$ interaction was examined in one particular complex, the dimer of $\mathrm{Me}_{3} \mathrm{SCN}^{73}$, which yielded a binding energy of $7.6 \mathrm{kcal} / \mathrm{mol}$. Of perhaps greater import for the work described here, the MP2/aug-cc-pVDZ treatment, as was applied here, provided a binding energy within $0.4 \mathrm{kcal} / \mathrm{mol}$ of a $\operatorname{CCSD}(\mathrm{T})$ estimate with extrapolation to complete basis set. Within a clathrate structure which comprises two tetrel bonds, the interaction diminishes in the order $\mathrm{Sn}>\mathrm{Ge}>\mathrm{Si}^{41}$, but a somewhat different pattern of $\mathrm{Sn}>\mathrm{Si}>\mathrm{Ge}>\mathrm{C}$ was observed ${ }^{44}$ for complexes including $\mathrm{TH}_{3} \mathrm{~F}$. This ambiguity vis a vis $\mathrm{Si}$ vs $\mathrm{Ge}$, observed in the calculations presented above, was amplified in tetrel bonds where the Lewis base is a carbene ${ }^{70}$ and when the tetrel atom is bound to an aromatic ring ${ }^{39}$. Due to its partial negative charge, the $\mathrm{H}$ atom of a metal hydride can be considered as a Lewis base. When interacting with a tetrel atom ${ }^{74}$ one gets a tetrel bond that is not entirely different than that wherein a $\mathrm{N}$ lone pair serves as electron donor. These interactions displayed the $\mathrm{Sn}>\mathrm{Si}>\mathrm{Ge}>\mathrm{C}$ trend expected for tetrel bonds in general.

Tetrel atoms all the way up to $\mathrm{Pb}$ were considered ${ }^{75}$ in the framework of their interactions with $\mathrm{CO}$, admittedly not a strong base. These interactions were magnified by the placement of a full positive charge on the Lewis acid in these trivalent, rather than tetravalent, $\mathrm{CX}_{3}{ }^{+}$cations. These two deviations from typical neutral tetrel bonds apparently caused certain discrepancies from the usual trends. Rather than the expected strengthening as one moves down the tetrel column of the periodic table, Si engaged in the strongest interactions, followed by Ge and then by Sn. In fact, the strongest interactions of all involved the $\mathrm{CH}_{3}{ }^{+}$cation. 


\section{REFERENCES}

1. Gilli, G.; Gilli, P. The Nature of the Hydrogen Bond. Oxford University Press: Oxford, UK, 2009 ; p 313.

2. Desiraju, G. R.; Steiner, T. The Weak Hydrogen Bond in Structural Chemistry and Biology. Oxford: New York, 1999; p 507.

3. Scheiner, S. Hydrogen Bonding. A Theoretical Perspective. Oxford University Press: New York, 1997; p 375 .

4. Alkorta, I.; Rozas, S.; Elguero, J. Charge-Transfer Complexes between Dihalogen Compounds and Electron Donors. J. Phys. Chem. A 1998, 102, 9278-9285.

5. Karpfen, A. Charge-Transfer Complexes between $\mathrm{NH}_{3}$ and the Halogens $\mathrm{F}_{2}, \mathrm{ClF}$, and $\mathrm{Cl}_{2}$,: An Ab Initio Study on the Intermolecular Interaction. J. Phys. Chem. A 2000, 104, 6871-6879.

6. Riley, K. E.; Merz, K. M. Insights into the Strength and Origin of Halogen Bonding: The HalobenzeneFormaldehyde Dimer. J. Phys. Chem. A 2007, 111, 1688-1694.

7. Riley, K. E.; Ford Jr, C. L.; Demouchet, K. Comparison of Hydrogen Bonds, Halogen Bonds, CH“П Interactions, and CX $\Pi$ Interactions Using High-Level Ab Initio Methods. Chem. Phys. Lett. 2015, 621, 165-170.

8. Bauzá, A.; Frontera, A. Competition between Halogen Bonding and П-Hole Interactions Involving Various Donors: The Role of Dispersion Effects. ChemPhysChem. 2015, 16, 3108-3113.

9. Politzer, P.; Murray, J. S. A Unified View of Halogen Bonding, Hydrogen Bonding and Other $\sigma$-Hole Interactions. In Noncovalent Forces, Scheiner, S., Ed. Springer: Dordrecht, Netherlands, 2015; Vol. 19, pp 357-389.

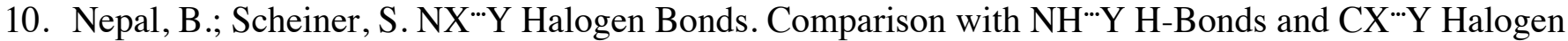
Bonds. Phys. Chem. Chem. Phys. 2016, 18, 18015-18023.

11. Iwaoka, M.; Komatsu, H.; Katsuda, T.; Tomoda, S. Quantitative Evaluation of Weak Nonbonded Se $\cdots$ F Interactions and Their Remarkable Nature as Orbital Interactions. J. Am. Chem. Soc. 2002, 124, 19021909.

12. Nziko, V.d. P. N.; Scheiner, S. S $\cdots \Pi$ Chalcogen Bonds between $\mathrm{SF}_{2}$ or $\mathrm{SF}_{4}$ and C-C Multiple Bonds. $J$. Phys. Chem. A 2015, 119, 5889-5897.

13. Sanz, P.; Mó, O.; Yáñez, M. Characterization of Intramolecular Hydrogen Bonds and Competitive Chalcogen-Chalcogen Interactions on the Basis of the Topology of the Charge Density. Phys. Chem. Chem. Phys. 2003, 5, 2942-2947.

14. Azofra, L. M.; Alkorta, I.; Scheiner, S. Chalcogen Bonds in Complexes of SOXY (X, Y = F, Cl) with Nitrogen Bases. J. Phys. Chem. A 2015, 119, 535-541.

15. Scheiner, S. Effects of Multiple Substitution Upon the P'N Noncovalent Interaction. Chem. Phys. 2011, 387, 79-84.

16. Esrafili, M. D.; Mohammadian-Sabet, F. Homonuclear Chalcogen-Chalcogen Bond Interactions in Complexes Pairing $\mathrm{YO}_{3}$ and $\mathrm{Yhx}$ Molecules $\left(\mathrm{Y}=\mathrm{S}, \mathrm{Se} ; \mathrm{X}=\mathrm{H}, \mathrm{Cl}, \mathrm{Br}, \mathrm{CCH}, \mathrm{NC}, \mathrm{OH}, \mathrm{OCH}_{3}\right)$ : Influence of Substitution and Cooperativity. Int. J. Quantum Chem. 2016, 116, 529-536.

17. Bauzá, A.; Mooibroek, T. J.; Frontera, A. $\Sigma$-Hole Opposite to a Lone Pair: Unconventional Pnicogen Bonding Interactions between $\mathrm{ZF}_{3}(\mathrm{Z}=\mathrm{N}, \mathrm{P}, \mathrm{As}$, and $\mathrm{Sb}$ ) Compounds and Several Donors. ChemPhysChem. 2016, 17, 1608-1614.

18. Del Bene, J. E.; Alkorta, I.; Elguero, J. The Pnicogen Bond in Review: Structures, Energies, Bonding Properties, and Spin-Spin Coupling Constants of Complexes Stabilized by Pnicogen Bonds. In Noncovalent Forces, Scheiner, S., Ed. Springer: Dordrecht, Netherlands, 2015; Vol. 19, pp 191-263.

19. Scheiner, S. Can Two Trivalent N Atoms Engage in a Direct N"N Noncovalent Interaction? Chem. Phys. Lett. 2011, 514, 32-35.

20. Sanchez-Sanz, G.; Trujillo, C.; Alkorta, I.; Elguero, J. Modulating Intramolecular P'NN Pnictogen Interactions. Phys. Chem. Chem. Phys. 2016, 18, 9148-9160. 
21. Scheiner, S.; Adhikari, U. Abilities of Different Electron Donors (D) to Engage in a P*-D Noncovalent Interaction. J. Phys. Chem. A 2011, 115, 11101-11110.

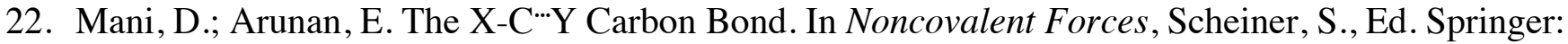
Heidelberg, 2015; pp 323-356.

23. Alkorta, I.; Rozas, I.; Elguero, J. Molecular Complexes between Silicon Derivatives and Electron-Rich Groups. J. Phys. Chem. A 2001, 105, 743-749.

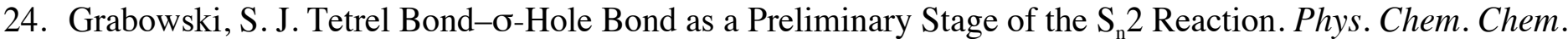
Phys. 2014, 16, 1824-1834.

25. Scheiner, S. Comparison of $\mathrm{CH}^{\cdots} \mathrm{O}, \mathrm{SH} \cdots \mathrm{O}$, Chalcogen, and Tetrel Bonds Formed by Neutral and Cationic Sulfur-Containing Compounds. J. Phys. Chem. A 2015, 119, 9189-9199.

26. McDowell, S. A. C. Sigma-Hole Cooperativity in Anionic $\left[\mathrm{FX}^{*} \mathrm{CH}_{3}{ }^{-} \mathrm{YF}\right]^{-}(\mathrm{X}, \mathrm{Y}=\mathrm{Cl}, \mathrm{Br})$ Complexes. Chem. Phys. Lett. 2014, 598, 1-4.

27. Bauzá, A.; Frontera, A. $\mathrm{RCH}_{3} \cdots \mathrm{O}$ Interactions in Biological Systems: Are They Trifurcated H-Bonds or Noncovalent Carbon Bonds? Cryst. 2016, 6, 26.

28. Mani, D.; Arunan, E. The $\mathrm{X}-\mathrm{C} \cdots \pi(\mathrm{X}=\mathrm{F}, \mathrm{Cl}, \mathrm{Br}, \mathrm{CN})$ Carbon Bond. J. Phys. Chem. A 2014, 118, 1008110089.

29. Guo, X.; Liu, Y.-W.; Li, Q.-Z.; Li, W.-Z.; Cheng, J.-B. Competition and Cooperativity between Tetrel Bond and Chalcogen Bond in Complexes Involving $\mathrm{F}_{2} \mathrm{CX}(\mathrm{X}=\mathrm{Se}$ and Te $)$. Chem. Phys. Lett. 2015, 620, 712.

30. Azofra, L. M.; Scheiner, S. Tetrel, Chalcogen, and CH“O Hydrogen Bonds in Complexes Pairing Carbonyl-Containing Molecules with 1, 2, and 3 Molecules of $\mathrm{CO}_{2}$. J. Chem. Phys. 2015, 142, 034307.

31. Esrafili, M. D.; Mohammadian-Sabet, F. Cooperativity of Tetrel Bonds Tuned by Substituent Effects. Mol. Phys. 2016, 114, 1528-1538.

32. Marín-Luna, M.; Alkorta, I.; Elguero, J. Cooperativity in Tetrel Bonds. J. Phys. Chem. A 2016, 120, 648656.

33. Nziko, V. d. P. N.; Scheiner, S. Comparison of $\pi$-Hole Tetrel Bonding with $\sigma$-Hole Halogen Bonds in Complexes of XCN (X = F, Cl, Br, I) and $\mathrm{NH}_{3}$. Phys. Chem. Chem. Phys. 2016, 18, 3581-3590.

34. Del Bene, J. E.; Alkorta, I.; Elguero, J. Anionic Complexes of $\mathrm{F}^{-}$and $\mathrm{Cl}^{-}$with Substituted Methanes: Hydrogen, Halogen, and Tetrel Bonds. Chem. Phys. Lett. 2016, 655-656, 115-119.

35. Vojinović, K.; McLachlan, L. J.; Hinchley, S. L.; Rankin, D. W. H.; Mitzel, N. W. Strong Intramolecular Secondary Si“'N Bonds in Trifluorosilylhydrazines. Chem. Eur. J. 2004, 10, 3033-3042.

36. Rossi, A. R.; Jasinski, J. M. Theoretical Studies of Neutral Silane-Ammonia Adducts. Chem. Phys. Lett. 1990, 169, 399-404.

37. Schoeller, W. W.; Rozhenko, A. Pentacoordination at Fluoro-Substituted Silanes by Weak Lewis Donor Addition. Eur. J. Inorg. Chem 2000, 2000, 375-381.

38. Tang, Q.; Li, Q. Interplay between Tetrel Bonding and Hydrogen Bonding Interactions in Complexes Involving $\mathrm{F}_{2} \mathrm{XO}(\mathrm{X}=\mathrm{C}$ and $\mathrm{Si})$ and $\mathrm{HCN}$. Comput. Theor. Chem. 2014, 1050, 51-57.

39. Liu, M.; Li, Q.; Scheiner, S. Comparison of Tetrel Bonds in Neutral and Protonated Complexes of Pyridine $\mathrm{TF}_{3}$ and FuranTF $\left(\mathrm{T}=\mathrm{C}, \mathrm{Si}\right.$, and Ge) with $\mathrm{NH}_{3}$. Phys. Chem. Chem. Phys. 2017, 19, 5550-5559.

40. Liu, M.; Li, Q.; Li, W.; Cheng, J. Tetrel Bonds between Pysix3 and Some Nitrogenated Bases: Hybridization, Substitution, and Cooperativity. Journal of Molecular Graphics and Modelling 2016, 65, 35-42.

41. Bauzá, A.; Mooibroek, T. J.; Frontera, A. Tetrel-Bonding Interaction: Rediscovered Supramolecular Force? Angew. Chem. Int. Ed. 2013, 52, 12317-12321.

42. Bauzá, A.; Ramis, R.; Frontera, A. Computational Study of Anion Recognition Based on Tetrel and Hydrogen Bonding Interaction by Calix[4]Pyrrole Derivatives. Comput. Theor. Chem. 2014, 1038, 67-70.

43. Scheiner, S. Assembly of Effective Halide Receptors from Components. Comparing Hydrogen, Halogen, and Tetrel Bonds. J. Phys. Chem. A 2017, 121, 3606-3615. 
44. Liu, M.; Li, Q.; Cheng, J.; Li, W.; Li, H.-B. Tetrel Bond of Pseudohalide Anions with $\mathrm{XH}_{3} \mathrm{~F}(\mathrm{X}=\mathrm{C}, \mathrm{Si}$, Ge, and Sn) and Its Role in Sn2 Reaction. J. Chem. Phys. 2016, 145, 224310.

45. Scheiner, S. Highly Selective Halide Receptors Based on Chalcogen, Pnicogen, and Tetrel Bonds. Chem. Eur. J. 2016, 22, 18850-18858.

46. Frisch, M. J.; Trucks, G. W.; Schlegel, H. B.; Scuseria, G. E.; Robb, M. A.; Cheeseman, J. R.; Scalmani, G.; Barone, V.; Mennucci, B.; Petersson, G. A., et al. Gaussian 09, Revision B.01; Wallingford, CT, 2009.

47. Feller, D. The Role of Databases in Support of Computational Chemistry Calculations. J. Comput. Chem. 1996, $17,1571-1586$.

48. Schuchardt, K. L.; Didier, B. T.; Elsethagen, T.; Sun, L.; Gurumoorthi, V.; Chase, J.; Li, J.; Windus, T. L. Basis Set Exchange: A Community Database for Computational Sciences. J. Chem. Infor. Model. 2007, 47, 1045-1052.

49. Wang, Y.; Zeng, Y.; Li, X.; Meng, L.; Zhang, X. The Mutual Influence between П-Hole Pnicogen Bonds and $\Sigma$-Hole Halogen Bonds in Complexes of $\mathrm{PO}_{2} \mathrm{Cl}$ and $\mathrm{XCN} / \mathrm{C}_{6} \mathrm{H}_{6}(\mathrm{X}=\mathrm{f}, \mathrm{Cl}, \mathrm{Br}$ ). Struct. Chem. 2016, 27, 1427-1437.

50. Spada, L.; Gou, Q.; Geboes, Y.; Herrebout, W. A.; Melandri, S.; Caminati, W. Rotational Study of Dimethyl Ether-Chlorotrifluoroethylene: Lone Pair $\cdots \Pi$ Interaction Links the Two Subunits. J. Phys. Chem. A 2016, 120, 4939-4943.

51. Shukla, R.; Chopra, D. "Pnicogen Bonds" or "Chalcogen Bonds": Exploiting the Effect of Substitution on the Formation of P'-Se Noncovalent Bonds. Phys. Chem. Chem. Phys. 2016, 18, 13820-13829.

52. Tang, Q.; Li, Q. Non-Additivity of F Substituent in Enhancing the Halogen Bond in $\mathrm{C}_{6} \mathrm{H}_{5} \mathrm{I}$ 'NCH. Comput. Theor. Chem. 2015, 1070, 21-26.

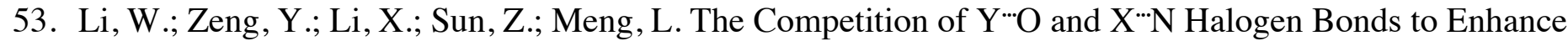
the Group $\mathrm{V} \sum$-Hole Interaction in the $\mathrm{NCY}{ }^{\cdots} \mathrm{O}=\mathrm{PH}_{3}{ }^{\cdots} \mathrm{NCX}$ and $\mathrm{O}=\mathrm{PH}_{3}{ }^{\cdots} \mathrm{NCX} \cdots \mathrm{NCY}(\mathrm{X}, \mathrm{Y}=\mathrm{F}, \mathrm{Cl}$, and $\mathrm{Br})$ Complexes. J. Comput. Chem. 2015, 36, 1349-1358.

54. Geboes, Y.; Proft, F. D.; Herrebout, W. A. Expanding Lone Pair $\cdots$ I Interactions to Nonaromatic Systems and Nitrogen Bases: Complexes of $\mathrm{C}_{2} \mathrm{~F}_{3} \mathrm{X}(\mathrm{X}=\mathrm{F}, \mathrm{Cl}, \mathrm{Br}, \mathrm{I})$ and TMA-D9. J. Phys. Chem. A 2015, 119, 5597-5606.

55. Lang, T.; Li, X.; Meng, L.; Zheng, S.; Zeng, Y. The Cooperativity between the $\Sigma$-Hole and $\Pi$-Hole Interactions in the $\mathrm{ClO} \cdots \mathrm{XONO}_{2} / \mathrm{XONO} \cdots \mathrm{NH}_{3}(\mathrm{X}=\mathrm{cl}, \mathrm{Br}, \mathrm{I})$ Complexes. Struct. Chem. 2015, 26, $213-221$.

56. Sutradhar, D.; Chandra, A. K.; Zeegers-Huyskens, T. A Theoretical Investigation of the Interaction between Fluorinated Dimethyl Ethers and Molecular Chlorine. Mol. Phys. 2014, 112, 2791-2801.

57. Sanchez-Sanz, G.; Trujillo, C.; Alkorta, I.; Elguero, J. Intramolecular Pnicogen Interactions in Phosphorus and Arsenic Analogues of Proton Sponges. Phys. Chem. Chem. Phys. 2014, 16, 15900-15909.

58. Chen, Y.; Yao, L.; Lin, X. Theoretical Study of $\left(\mathrm{FH}_{2} \mathrm{X}\right)_{\mathrm{n}} \cdot \mathrm{Y}\left(\mathrm{X}=\mathrm{P}\right.$ and $\mathrm{As}, \mathrm{n}=1-4, \mathrm{Y}^{-} \mathrm{F}^{-}, \mathrm{Cl}^{-}, \mathrm{Br}^{-}, \mathrm{I}^{-}, \mathrm{NO}_{3}^{-}$ and $\left.\mathrm{SO}_{4}{ }^{2-}\right)$ : The Possibility of Anion Recognition Based on Pnicogen Bonding. Comput. Theor. Chem. 2014, 1036, 44-50.

59. Esrafili, M. D.; Fatehi, P.; Solimannejad, M. Mutual Interplay between Pnicogen Bond and Dihydrogen Bond in $\mathrm{HMH}$ ' $\mathrm{HCN} \cdots \mathrm{PH}_{2} \mathrm{X}$ Complexes $(\mathrm{M}=\mathrm{Be}, \mathrm{Mg}, \mathrm{Zn} ; \mathrm{X}=\mathrm{H}, \mathrm{F}, \mathrm{Cl})$. Comput. Theor. Chem. 2014, 1034, 1-6.

60. Hauchecorne, D.; Herrebout, W. A. Experimental Characterization of C-X $\cdots Y-C(X=B r, I ; Y=F, C l)$ Halogen-Halogen Bonds. J. Phys. Chem. A 2013, 117, 11548-11557.

61. Liu, X.; Cheng, J.; Li, Q.; Li, W. Competition of Hydrogen, Halogen, and Pnicogen Bonds in the Complexes of $\mathrm{HArF}$ with $\mathrm{XH}_{2} \mathrm{P}(\mathrm{X}=\mathrm{F}, \mathrm{Cl}$, and $\mathrm{Br})$. Spectrochim. Acta A 2013, 101, 172-177.

62. Boys, S. F.; Bernardi, F. The Calculation of Small Molecular Interactions by the Differences of Separate Total Energies. Some Procedures with Reduced Errors. Mol. Phys. 1970, 19, 553-566.

63. Zhurko, G. A. Chemcraft; http://www.Chemcraftprog.Com. 
64. Bulat, F. A.; Toro-Labbé, A.; Brinck, T.; Murray, J. S.; Politzer, P. Quantitative Analysis of Molecular Surfaces: Areas, Volumes, Electrostatic Potentials and Average Local Ionization Energies. J. Mol. Model. 2010, 16, 1679-1691.

65. Glendening, E. D.; Landis, C. R.; Weinhold, F. NBO 6.0: Natural Bond Orbital Analysis Program. J. Comput. Chem. 2013, 34, 1429-1437.

66. Bader, R. F. W.; Carroll, M. T.; Cheeseman, J. R.; Chang, C. Properties of Atoms in Molecules: Atomic Volumes. J. Am. Chem. Soc. 1987, 109, 7968-7979.

67. Bader, R. F. W. Atoms in Molecules, A Quantum Theory. Clarendon Press: Oxford, 1990; Vol. 22 , p 438.

68. Keith, T. A. Aimall, TK Gristmill Software: Overland Park KS, 2013.

69. Quinonero, D. Sigma-Hole Carbon-Bonding Interactions in Carbon-Carbon Double Bonds: An Unnoticed Contact. Phys. Chem. Chem. Phys. 2017, 19, 15530-15540.

70. Liu, M.; Li, Q.; Li, W.; Cheng, J. Carbene Tetrel-Bonded Complexes. Struct. Chem. 2017, $28,823-831$.

71. Marín-Luna, M.; Alkorta, I.; Elguero, J. A Theoretical Study of the $\mathrm{H}_{\mathrm{n}} \mathrm{f}_{4-\mathrm{N}}$ si:N-Base $(\mathrm{n}=1-4)$ TetrelBonded Complexes. Theor. Chem. Acc. 2017, 136, 41-.

72. Marín-Luna, M.; Alkorta, I.; Elguero, J. Theoretical Study of the Geometrical, Energetic and NMR Properties of Atranes. J. Organomet. Chem. 2015, 794, 206-215.

73. Matczak, $\mathrm{P}$. Theoretical Investigation of the $\mathrm{N}$ Sn Coordination in $\left(\mathrm{Me}_{3} \mathrm{SnCN}\right)_{2}$. Struct. Chem. 2015, 26, 301-318.

74. Li, Q.-Z.; Zhuo, H.-Y.; Li, H.-B.; Liu, Z.-B.; Li, W.-Z.; Cheng, J.-B. Tetrel-Hydride Interaction between $\mathrm{XH}_{3} \mathrm{~F}(\mathrm{X}=\mathrm{C}, \mathrm{Si}, \mathrm{Ge}, \mathrm{Sn})$ and $\mathrm{HM}(\mathrm{M}=\mathrm{Li}, \mathrm{Na}, \mathrm{BeH}, \mathrm{MgH})$. J. Phys. Chem. A 2015, 119, 2217-2224.

75. Ghara, M.; Pan, S.; Kumar, A.; Merino, G.; Chattaraj, P. K. Structure, Stability, and Nature of Bonding in Carbon Monoxide Bound $\mathrm{EX}_{3}{ }^{+}$Complexes $(\mathrm{E}=$ Group 14 Element; $\mathrm{X}=\mathrm{H}, \mathrm{F}, \mathrm{Cl}, \mathrm{Br}, \mathrm{I})$. J. Comput. Chem. 2016, 37, 2202-2211. 
Table 1. Intermolecular distance $\mathrm{R}(\mathrm{T} \cdot \mathrm{N})$ and stretch of internal T-X bond in Lewis acid molecule, with $\mathrm{X}$ lying opposite to $\mathrm{N}$.

\begin{tabular}{|l|l|l|l|l|l|l|l|c|}
\hline & \multicolumn{5}{|c|}{$\mathrm{R}(\mathrm{T} \cdot \mathrm{N}), \AA$} & \multicolumn{4}{c|}{$\Delta \mathrm{r}(\mathrm{T}-\mathrm{X}), \AA$} \\
\hline & $\mathrm{TH}_{4}$ & $\mathrm{TH}_{3} \mathrm{~F}$ & $\mathrm{TF}_{3} \mathrm{H}$ & $\mathrm{TF}_{4}$ & $\mathrm{TH}_{4}$ & $\mathrm{TH}_{3} \mathrm{~F}$ & $\mathrm{TF}_{3} \mathrm{H}$ & $\mathrm{TF}_{4}$ \\
\hline $\mathrm{T}=\mathrm{C}$ & - & 3.159 & - & 3.397 & - & 0.0063 & - & 0.0057 \\
\hline $\mathrm{T}=\mathrm{Si}$ & 3.243 & 2.557 & 2.088 & 2.054 & 0.0070 & 0.0254 & 0.0165 & 0.0370 \\
\hline $\mathrm{T}=\mathrm{Ge}$ & 3.332 & 2.629 & 2.128 & 2.105 & 0.0090 & 0.0321 & 0.0163 & 0.0311 \\
\hline $\mathrm{T}=\mathrm{Sn}$ & 3.169 & 2.668 & 2.287 & 2.279 & 0.0168 & 0.0339 & 0.0147 & 0.0187 \\
\hline
\end{tabular}

Table 2. Energetics of association reactions of indicated Lewis acid with $\mathrm{NH}_{3}$.

\begin{tabular}{|l|l|l|l|l|l|l|l|l|}
\hline & \multicolumn{4}{|c|}{$\Delta \mathrm{E}^{\text {elec }}, \mathrm{kcal} / \mathrm{mol}$} & \multicolumn{4}{c|}{$\Delta \mathrm{G}, \mathrm{kcal} / \mathrm{mol}$} \\
\hline & \multicolumn{1}{|c|}{$\mathrm{TH}_{4}$} & $\mathrm{TH}_{3} \mathrm{~F}$ & \multicolumn{1}{|c|}{$\mathrm{TF}_{3} \mathrm{H}$} & $\mathrm{TF}_{4}$ & $\mathrm{TH}_{4}$ & $\mathrm{TH}_{3} \mathrm{~F}$ & $\mathrm{TF}_{3} \mathrm{H}$ & $\mathrm{TF}_{4}$ \\
\hline $\mathrm{T}=\mathrm{C}$ & - & -1.84 & - & -0.82 & - & 4.87 & - & 6.76 \\
\hline $\mathrm{T}=\mathrm{Si}$ & -1.66 & -5.49 & -4.75 & -10.59 & 4.85 & 4.23 & 8.05 & 2.52 \\
\hline $\mathrm{T}=\mathrm{Ge}$ & -1.48 & -5.84 & -8.68 & -16.77 & 5.06 & 4.12 & 3.85 & -4.01 \\
\hline $\mathrm{T}=\mathrm{Sn}$ & -2.44 & -8.51 & -18.20 & -25.53 & 4.90 & 1.68 & -6.33 & -13.41 \\
\hline
\end{tabular}

Table 3. Electron density of AIM bond critical point connecting $\mathrm{T}$ to $\mathrm{N}$.

\begin{tabular}{|l|l|l|l|l|}
\hline & \multicolumn{4}{|c|}{$\varrho_{\mathrm{BCP}}$, au } \\
\hline & $\mathrm{TH}_{4}$ & $\mathrm{TH}_{3} \mathrm{~F}$ & \multicolumn{1}{|c|}{$\mathrm{TF}_{3} \mathrm{H}$} & $\mathrm{TF}_{4}$ \\
\hline $\mathrm{T}=\mathrm{C}$ & - & 0.0068 & - & 0.0047 \\
\hline $\mathrm{T}=\mathrm{Si}$ & 0.0084 & 0.0256 & 0.0581 & 0.0623 \\
\hline $\mathrm{T}=\mathrm{Ge}$ & 0.0077 & 0.0245 & 0.0703 & 0.0741 \\
\hline $\mathrm{T}=\mathrm{Sn}$ & 0.0120 & 0.0286 & 0.0617 & 0.0630 \\
\hline
\end{tabular}


Table 4. Measures of charge transfer from $\mathrm{NH}_{3}$ to Lewis acid

\begin{tabular}{|l|l|l|l|l|l|l|l|l|l|l|l|l|l|}
\hline & \multicolumn{4}{|c|}{$\mathrm{NBO}(2)_{1}{ }^{\mathrm{a}}, \mathrm{kcal} / \mathrm{mol}$} & \multicolumn{4}{c|}{$\mathrm{NBO} \mathrm{E}(2)_{2}{ }^{\mathrm{b}}, \mathrm{kcal} / \mathrm{mol}$} & \multicolumn{4}{|c|}{$\mathrm{q}_{\left(\mathrm{NH}_{3}\right)^{\mathrm{d}}, \mathrm{e}}$} \\
\hline & $\mathrm{TH}_{4}$ & $\mathrm{TH}_{3} \mathrm{~F}$ & $\mathrm{TF}_{3} \mathrm{H}$ & $\mathrm{TF}_{4}$ & $\mathrm{TH}_{4}$ & $\mathrm{TH}_{3} \mathrm{~F}$ & $\mathrm{TF}_{3} \mathrm{H}$ & $\mathrm{TF}_{4}$ & $\mathrm{TH}_{4}$ & $\mathrm{TH}_{3} \mathrm{~F}$ & $\mathrm{TF}_{3} \mathrm{H}$ & $\mathrm{TF}_{4}$ \\
\hline $\mathrm{T}=\mathrm{C}$ & - & 1.68 & - & 0.15 & - & - & - & - & - & 0.021 & - & 0.000 \\
\hline $\mathrm{T}=\mathrm{Si}$ & 3.14 & 16.04 & 15.69 & $16.55^{\mathrm{c}}$ & 0.61 & 3.18 & 23.98 & $15.85^{\mathrm{c}}$ & 0.016 & 0.073 & 0.166 & 0.165 \\
\hline $\mathrm{T}=\mathrm{Ge}$ & 3.02 & 14.75 & 12.86 & $18.68^{\mathrm{c}}$ & 0.59 & 2.99 & 26.76 & $23.90^{\mathrm{c}}$ & 0.015 & 0.068 & 0.171 & 0.169 \\
\hline $\mathrm{T}=\mathrm{Sn}$ & 5.68 & 16.47 & $10.68^{\mathrm{c}}$ & $10.72^{\mathrm{c}}$ & 1.91 & 5.90 & $25.35^{\mathrm{c}}$ & $20.45^{\mathrm{c}}$ & 0.029 & 0.064 & 0.141 & 0.132 \\
\hline
\end{tabular}

${ }^{a}$ charge transfer from $\mathrm{N}$ lone pair to $\sigma^{*}(\mathrm{~T}-\mathrm{X})$ antibonding orbital with $\mathrm{X}$ opposite to $\mathrm{N}$

${ }^{b}$ charge transfer from $\mathrm{N}$ lone pair to $\sigma^{*}(\mathrm{~T}-\mathrm{X})$ antibonding orbital with $\mathrm{X}$ not opposite to $\mathrm{N}$

charge transfer from $\sigma(\mathrm{T}-\mathrm{N})$ orbital

dotal natural charge residing on $\mathrm{NH}_{3}$ molecule

Table 5. Maximum value of electrostatic potential on isodensity surface corresponding to $\varrho=0.001 \mathrm{au}$.

\begin{tabular}{|l|r|r|r|r|}
\hline & \multicolumn{4}{|c|}{$\mathrm{V}_{\text {s,max }}, \mathrm{kcal} / \mathrm{mol}$} \\
\hline & \multicolumn{1}{|c|}{$\mathrm{TH}_{4}$} & \multicolumn{1}{c|}{$\mathrm{TH}_{3} \mathrm{~F}$} & \multicolumn{1}{c|}{$\mathrm{TF}_{3} \mathrm{H}$} & \multicolumn{1}{c|}{$\mathrm{TF}_{4}$} \\
\hline $\mathrm{T}=\mathrm{C}$ & - & 21.31 & 10.14 & 24.95 \\
\hline $\mathrm{T}=\mathrm{Si}$ & 19.39 & 41.13 & 34.80 & 49.98 \\
\hline $\mathrm{T}=\mathrm{Ge}$ & 17.80 & 45.06 & 34.22 & 58.76 \\
\hline $\mathrm{T}=\mathrm{Sn}$ & 24.25 & 53.67 & 45.40 & 74.52 \\
\hline
\end{tabular}

Table 6. Angular distortion imposed on Lewis acid molecule by formation of complex and resulting deformation energy

\begin{tabular}{|l|r|r|r|r|r|r|r|r|}
\hline & \multicolumn{4}{|c|}{$\Delta \theta(\mathrm{X}-\mathrm{T}-\mathrm{Y})$, degs } & \multicolumn{4}{c|}{$\mathrm{E}_{\text {def }}, \mathrm{kcal} / \mathrm{mol}$} \\
\hline & $\mathrm{TH}_{4}$ & \multicolumn{1}{|c|}{$\mathrm{TH}_{3} \mathrm{~F}$} & \multicolumn{1}{|c|}{$\mathrm{TF}_{3} \mathrm{H}$} & \multicolumn{1}{c|}{$\mathrm{TF}_{4}$} & \multicolumn{1}{c|}{$\mathrm{TH}_{4}$} & \multicolumn{1}{c|}{$\mathrm{H}_{3} \mathrm{~F}$} & $\mathrm{TF}_{3} \mathrm{H}$ & \multicolumn{1}{c|}{$\mathrm{TF}_{4}$} \\
\hline $\mathrm{T}=\mathrm{C}$ & - & 0.1 & - & -0.6 & - & 0.02 & - & 0.06 \\
\hline $\mathrm{T}=\mathrm{Si}$ & -1.4 & -4.9 & -12.6 & -12.7 & 0.14 & 1.93 & 21.38 & 20.78 \\
\hline $\mathrm{T}=\mathrm{Ge}$ & -1.2 & -4.6 & -12.9 & -12.5 & 0.11 & 1.51 & 18.99 & 16.61 \\
\hline $\mathrm{T}=\mathrm{Sn}$ & -2.5 & -5.3 & -12.0 & -11.0 & 0.37 & 1.77 & 12.50 & 9.62 \\
\hline
\end{tabular}




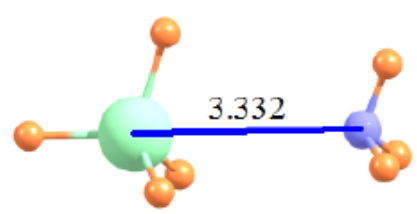

$\mathrm{GeH}_{4}$

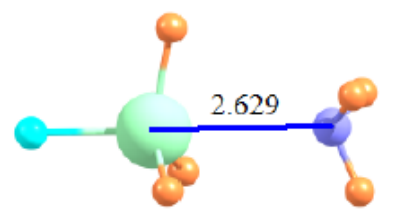

$\mathrm{GeH}_{3} \mathrm{~F}$

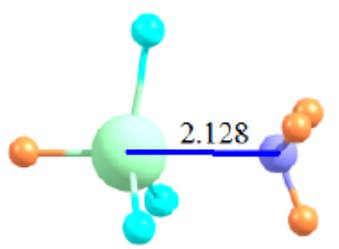

$\mathrm{GeF}_{3} \mathrm{H}$

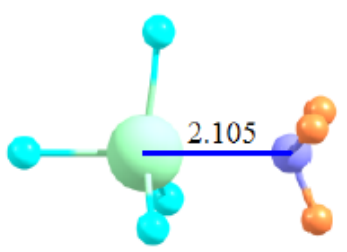

$\mathrm{GeF}_{4}$

Fig 1. Equilibrium geometries of indicated Ge-containing Lewis acid molecules with $\mathrm{NH}_{3}$, intermolecular distance in $\AA$. 


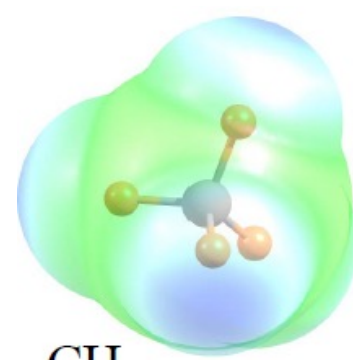

$\mathrm{CH}_{4}$

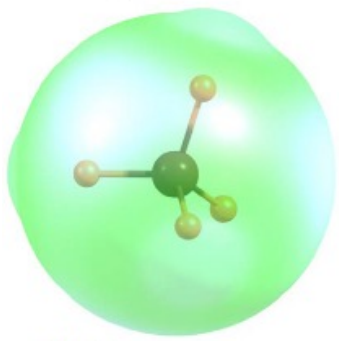

$\mathrm{SiH}_{4}$

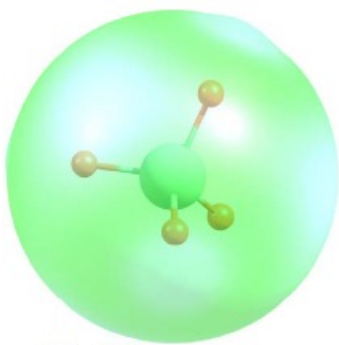

$\mathrm{GeH}_{4}$

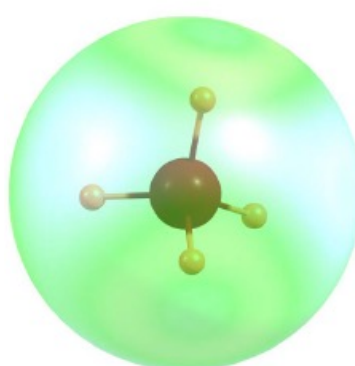

$\mathrm{SnH}_{4}$
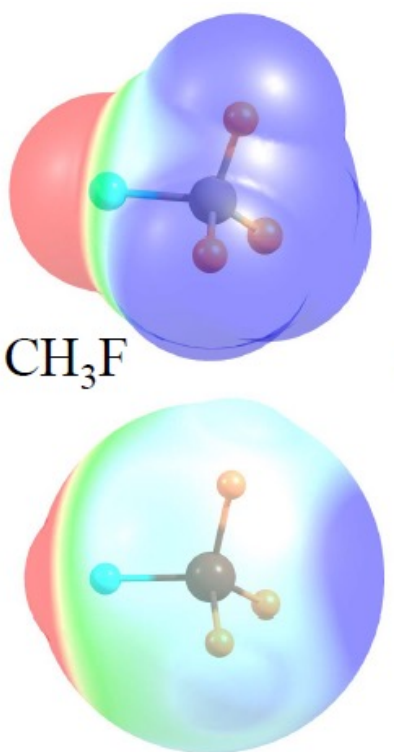

$\mathrm{SiH}_{3} \mathrm{~F}$

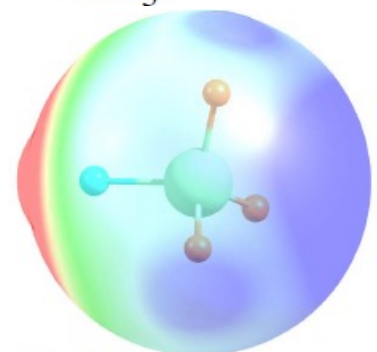

$\mathrm{GeH}_{3} \mathrm{~F}$

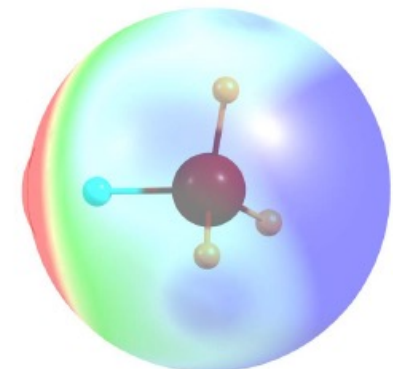

$\mathrm{SnH}_{3} \mathrm{~F}$

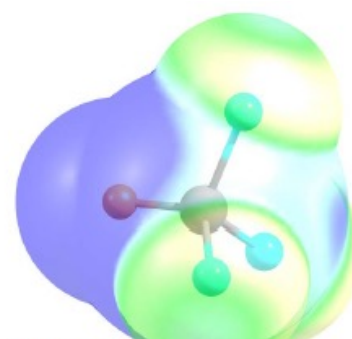

$\mathrm{CHF}_{3}$

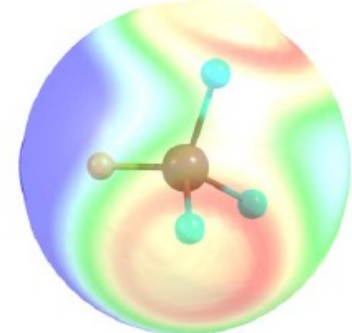

$\mathrm{SiHF}_{3}$

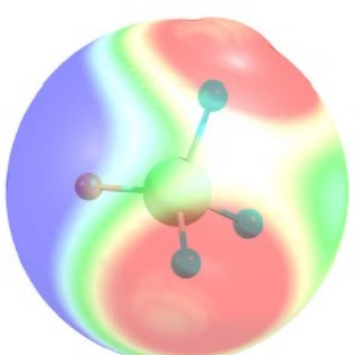

$\mathrm{GeHF}_{3}$

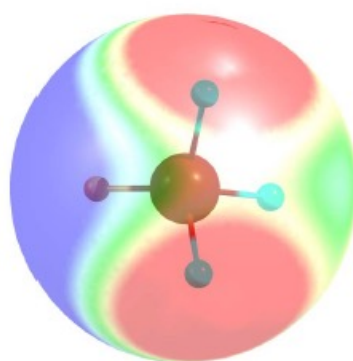

$\mathrm{SnHF}_{3}$
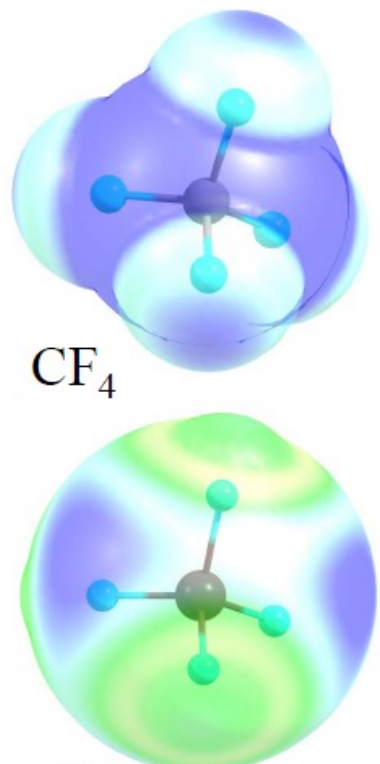

$\mathrm{SiF}_{4}$

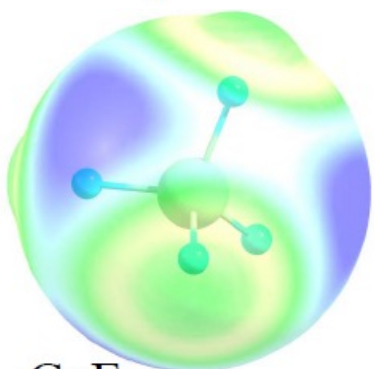

$\mathrm{GeF}_{4}$

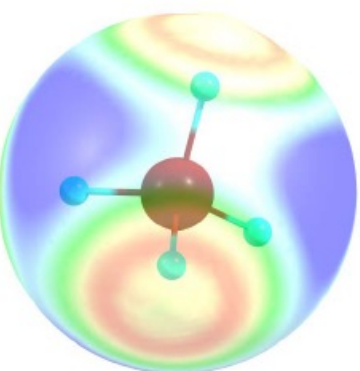

$\mathrm{SnF}_{4}$

Fig 2. Molecular electrostatic potentials of Lewis acid molecules, on surface corresponding to $1.5 \mathrm{x}$ van der Waals radius of each atom. Blue and red regions respectively refer to positive and negative potentials, with extrema of $\pm 0.02 \mathrm{au}$. 
Table of Contents Graphic

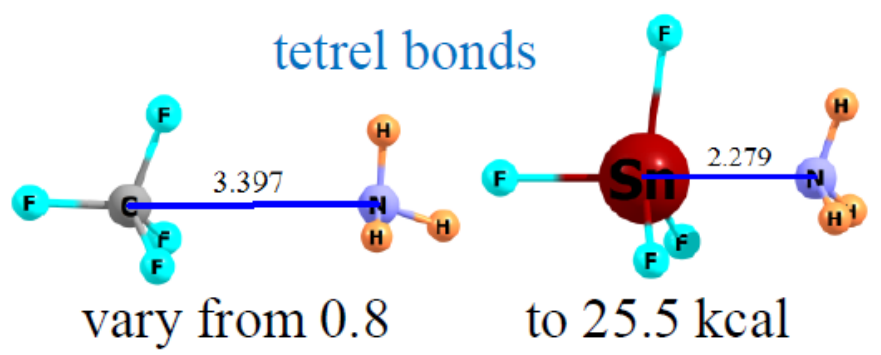

